\title{
AN ETHICAL APPROACH TO THE XENOPHOBIA AGAINST FOREIGNERS IN SOUTH AFRICA
}

\author{
Olu Ojedokun* \\ http://dx.doi.org/10.4314/og.v11i 1.9
}

\begin{abstract}
Solomon (2013) argues that Xenophobia, simply put, is the fear or hatred of foreigners or strangers; it is embodied in discriminatory attitudes and behaviour, and often culminates in violence, abuses of various types, and manifestations of hatred. Theoretically, he argues that the best and only solution is to remove enemy images; therefore, the goal of removal of the enemy images ought to be pursued with much conscientiousness. To this extent, this paper systematically attempts to deploy an ethical approach to explore the problem of xenophobia which has pervaded the attitudes of South Africans in recent times (Mnyaka, 2003). The work will attempt to uncover what has contributed to the enemy images of foreigners, and how such images can be removed from or, failing that, substantially ameliorated in the national consciousness of South Africans so as to change for the better, the current antipodal relations between indigenous South Africans and foreigners. Specifically, the work takes as its point of departure the ethical framework of Botho/Ubuntu to dialogue with the problem of the study, emphasizing the role of political leadership to this effect (Dalamo, 2013:7).
\end{abstract}

Keywords: Apartheid, Botho/Ubuntu, Ethics, South Africa, Xenophobia.

\section{Origins of Xenophobia in South Africa}

The issue of xenophobia can be traced back to pre-1994, when immigrants from elsewhere faced discrimination and even violence in South Africa, even though much of that risk stemmed from and was attributed to the institutionalized racism of the time due to apartheid (This Week: 2015). After advent of democracy in 1994, contrary to expectations, the incidence of xenophobia increased. According to Neocosmos (2010), between 2000 and March 2008, at least 67 people died in what were identified as xenophobic attacks. 
In May 2008, a series of riots left 62 people dead; although 21 of those killed were South African citizens. Landau (2011) asserts the attacks were apparently motivated by xenophobia. In 2015, another nationwide spike in xenophobic attacks against immigrants in general prompted a number of foreign governments to begin repatriating their citizens, Los Angles Times (2015).

South African History Online (2015) narrates the history of refugees and asylum seekers in South Africa stating that it dates back to the 1980s when the country was home to a number of Mozambican refugees, an estimated 350,000, of whom approximately $20 \%$ have since returned home. Under the old apartheid system South Africa did not recognise refugees until 1993 and when it became a signatory to the United Nations (UN) and Organisation of African Unity Conventions on Refugees in 1994, the number of refugees and asylum seekers in South Africa has increased in the past years, with the total number of cross-border migrants in this category at not more than 150 000. The issue regarding the number of undocumented migrants in the country has proved to be a controversial one. Central to this debate is the unquantifiable nature of this group of migrants together with a number of credible myths widely accepted as reality in South African society.

Currently, South Africa is Africa's most industrialised country, and it attracts thousands of foreign nationals every year, seeking refuge from poverty, economic crises, war and government persecution in their home countries. While the majority of them are from elsewhere on the continent, such as Zimbabwe, Malawi, Democratic Republic of Congo, Somalia and Ethiopia, many also come from Pakistan and Bangladesh. But what really is the definition of Xenophobia?

Solomon (2013) draws on the definition also used by the South African Human Rights Commission (SAHRC) describing Xenophobia as 'the deep dislike of non-nationals by nationals of a recipient state'. Mnyaka (2003) also attempts to address the definition of Xenophobia. Simply put, it is described as the fear or hatred of foreigners or strangers; it is embodied in discriminatory attitudes and behaviour and often culminates in violence, abuses of 
all types, and exhibitions of hatred (Mogekwu, 2005). Studies on xenophobia have attributed such hatred of foreigners to a number of causes: the fear of loss of social status and identity; a threat, perceived or real, to citizens' economic success; a way of reassuring the national self and its boundaries in times of national crisis (Harris 2001); a feeling of superiority; and poor intercultural information (Mogekwu 2005). According to the latter argument, Mogekwu (2005) states that xenophobes presumably do not have adequate information about the people they hate and, since they do not know how to deal with such people, they see them as a threat. Xenophobia basically derives from the sense that non-citizens pose some sort of a threat to the recipients' identity or their individual rights, and is also closely connected with the concept of nationalism: the sense in each individual of membership in the political nation as an essential ingredient in his or her sense of identity (Kaysen, 1996). To this end, a notion of citizenship can lead to xenophobia when it becomes apparent that the government does not guarantee protection of individual rights. This is all the more apparent where poverty and unemployment is rampant.

But South Africa's xenophobia in its peculiarity is also a manifestation of racism. Racism and xenophobia support each other and they share prejudiced discourses. They both operate on the same basis of profiling people and making negative assumptions. The profiling in the case of racism is on the basis of race, in the case of xenophobia on the basis of nationality. Solomon (2013:4) argues:

Possibly the most remarkable feature of xenophobia experienced in South Africa is that it appears to have taken on a primarily racial form; it is directed at migrants, and especially black migrants, from elsewhere on the continent, as opposed to, for example, Europeans or Americans, who are, to a certain extent, practically welcomed with open arms. This racially selective xenophobia is exemplified by the fact that many of those in leadership positions are of 'foreign' origin, suggesting that exclusion is not simply directed against 'foreigners' but against those who seem to 
correspond to stereotypes of the stranger, especially that from Africa (Neocosmos 2006).

One of the most striking findings of the SAMP survey is that, not only are Africans discriminated against, but that SADC citizens are not regarded any more favourably than Africans elsewhere on the continent. South Africans appear to believe that other SADC citizens take jobs from locals, commit crime, send their earnings out of the country, use the country's welfare services and bring diseases (Crush and Pendleton 2004). Such xenophobia is particularly problematic because of the historical universality of the struggle against apartheid and the unprecedented international, but mostly African, support it received in the 1980s. It is somewhat ironic that the Africans that currently face such exclusionary rhetoric hail from the same nations that harboured and nurtured the liberation struggles by providing sanctuary, education and sustenance to the fleeing comrades and cadres of the ANC who are today's gatekeepers (Nyamnjoh 2006). Opposition to the apartheid state served to unite, irrespective of nationality, and the identities thus constructed took on a pan-African context. Far from harbouring feelings of resentment and hatred towards migrants from neighbouring countries, should South Africans, and particularly black citizens, not feel something nearing gratitude and possibly a sense of comradeship with them? Why is it, then, that xenophobia appears to be so deeply ingrained into South African attitudes?

The paper hopes to address Solomon's (2013) question of how it appears xenophobia has become deeply ingrained in South African attitudes. The xenophobic violence that occurred in South Africa did not only affect victims who were foreigners but in fact everybody 
not belonging to the dominant ethnic groups in the main cities, Zulu or Xhosa were attacked. Members of smaller ethnic groups in South Africa are also viewed as foreigners by fellow South Africans. White people are not viewed as foreigners in the context of xenophobic violence. There had been attacks on South Africans who 'looked foreign' because they were 'too dark' to be South African.

The argument articulated in South African History Online (2015) states that the reasons for the attacks differ, with some blaming the contestation for scarce resources, others attribute it to the country's violent past, inadequate service delivery and the influence of micro politics in townships, involvement and complicity of local authority members in contractor conflicts for economic and political reasons, failure of early warning and prevention mechanisms regarding community-based violence; and also local residents claims that foreigners took jobs opportunities away from local south Africans and they accept lower wages, foreigners do not participate in the struggle for better wages and working conditions. Other local South Africans claim that foreigners are criminals, and they should not have access to services and police protection. Foreigners are also blamed for their businesses that take away customers from local residents and the spread of diseases such as HIV/AIDS. Other South African locals do not particularly like the presence of refugees, asylum-seekers or foreigners in their communities.

\section{Human Dignity in Ubuntu/Botho}

However, we cannot enter into a discourse of xenophobia without engagement in some literature in ethics surrounding Ubuntu. Mnyaka (2003) posits that the ANC government - in its attempts to overcome the division of the past and build new forms of social cohesion... embarked on an aggressive and inclusive nation-building project, which Ojedokun (2006) argues, it started with the conceptualization of Ubuntu during the Truth and Reconciliation Commission. Curiously, one unanticipated by-product of this project has been a growth in intolerance towards outsiders. Violence against foreign citizens and African refugees has become increasingly common and communities are divided by hostility and suspicion (Crush, 2004). 
Whilst xenophobia has been described as something of a global phenomenon, closely associated with the process of globalization, it has been noted that it is particularly prevalent in countries undergoing transition. According to Neocosmos (2006), this is because xenophobia is a problem of post-coloniality, one which is associated with the politics of the dominant groups in the period following independence. This is to do with a feeling of superiority, but is also perhaps, part of a 'scapegoating' process described by Harris (2001), where unfulfilled expectations of a new democracy result in the foreigner coming to embody unemployment, poverty and deprivation.

Theoretically, the best and only, solution is to remove enemy images; however, it is debatable whether this can be done. Enemy images may have their origin in a variety of genuine or perceived conflicts of interest, in racial prejudices, in traditional antagonisms between neigbouring competing tribes or groups, in imagined irreconcilable religious differences and so on (Gottstein 1996). This paper continues to explore why xenophobia has pervaded South African attitudes, what has contributed to enemy images of foreigners, and how, if at all such images can be removed from the national consciousness and we can better the current situation.

Mnyaka (2003) tries to explain the centrality of the human person in the philosophy of ubuntu/botho by drawing from others. According to Pato (1997:55) in ubuntu terms, human persons have dignity because they are created in the image of God 'though this belief is not expressed in explicit theological terms'. Being created in the image of God gives human beings their identity, their worth and humanity. Teffo (1988:4) says, 'the essence of man in ubuntu or African humanism lies in the recognition of man as man, before financial, political, and social factors are taken into consideration. Man is an end in himself and not a means. He is a touchstone of value'. Ubuntu is a term that refers to a human person, a human person who is the centre of everything. Human persons deserve respect and honour just because they are persons (abantu). There is no room for humiliation, discrimination and ill- treatment, but equal treatment and respect, which is supposed to be given to all human 
persons.

Metz (2007) agrees that South African ethics is closely bound up with the concept of Ubuntu, a philosophy of tolerance and compassion and that also embraces forgiveness. It suggests that if one persists in actions, which are undesirable, that person can be ostracised and rejected. This raises the question whether it is not the time that ubuntu should be demonstrated to the one in need of forgiveness. In ubuntu, there is room for forgiveness and not to have capacity for forgiveness would be to lack ubuntu. There are sayings such as "umntu akalahlwa" (one cannot completely discard a person for wrong doing) or "umntu akancanywa" (you cannot give up on a person). For Saule (1996:93) this is so because 'a person without ubuntu would have no peace of mind and might continue to hurt himself if he/she is not checked'. These two sayings promote and encourage forgiveness. The concern of these sayings:

...is not retribution or punishment but...healing of breaches, the redressing of imbalances, the restoration of broken relationships. This kind of justice seeks to rehabilitate both the victim and the perpetrator, who should be given the opportunity to be reintegrated into the community he or she has injured by his or her offence. This is a far more personal approach, which sees the offence as something that has happened to people and whose consequences is a rupture in relationships (Tutu, 1999:51-52).

The sayings express a hope that a person will improve and mend his or her ways. Attempts are always made to make sure that one is within the community and abides by the values, norms and practices of that particular community. Pressure will be exerted to make sure that good relations are maintained. From this it follows that there need not be any tension between individuality and community since it is possible for an individual freely to give up his/her own perceived interests for the survival of the community. But in giving up one's interest thus, one is also sure that the community will not disown one and that one's well-being will be its concern. It is a life 
of give and take...For the community is founded on notions of an intrinsic and enduring relationship among its members (Coetzee \& Roux, 1998:295-296).

Even though a person has been declared to be akanabuntu or akangomntu, the transgression that has been committed does not mean that one is not a member of the community. Furthermore it does not mean that one does not have a human nature or human dignity; his/her intrinsic value as a person is still there and that cannot be taken away. The only thing wrong with that person is the refusal to make use of his/her inner state, the state of being human, to do good acts for the well being of others and society. This sentiment is best addressed by Netshitomboni (1998:6) when he says:

This idiom [umntu akalahlwa] underscores the need for respect for human life and dignity whatever the circumstances. No matter what wrong an individual has done to the community, that individual remains a human being worthy of humane and equal treatment.

\section{The Moral Edge of Ubuntu/Botho}

Ubuntu is not an individualistic, abstract, cold and irrelevant spiritual way of life. It is being neighbourly; it has a strong social consciousness. This was said by Biko (1978:42) to be 'a deliberate act of God to make us a community of brothers and sisters jointly involved in the quest for a composite answer to varied problems of life'. Individuality only makes sense in so far as one relates to others in a humane and concrete way. Living in relation with others directly involves a person in social and moral roles, duties, obligations, and commitments, which the individual person must fulfill. The natural relationality of the person thus immediately plunges him/her into a moral universe, making morality an essentially social and transindividual phenomenon focused in the well being of others. Our natural sociality then prescribes or mandates a morality that clearly, should be weighted on the side of duty, i.e. on that which one has to do for others (Coetzee \& Roux, 1998:332). 
Ubuntu is inclusive and best realized and manifested in deeds of kindness, compassion, caring, sharing, solidarity and sacrifice. These acts produce positive results for both individuals and community. They make it possible for an individual to count on and expect the meaningful support of fellow human beings. People are enabled to share resources with which they are blessed. Furthermore, these values maintain and preserve the community together because they contribute positively to those in need.

A person in possession of such good qualities is considered ungumntu, unobuntu (a person who has humanity or humaneness). This recognises and affirms one's humanity. This recognition and affirmation reveal that it is only through the awareness that others have of us that we can become aware of ourselves as selfdetermining agents. Nor can the awareness that the other has of us be of just any kind at all. It must include the recognition that we are persons and, what is most important, a consent to us as such. In other words the other person must have an affirmative attitude to me, must recognize my value. Without this normal personal awareness and activity are impossible (Hartin et al.1991:190).

The idea that one ungumntu (is a person) shows that to have full personhood is to have managed to live out and demonstrated positive qualities which are beneficial to good neighbourliness, to have matured in positive human relations. Carrying out duties that contribute to the well being of others transforms and confers on an individual a full status of being a person. His/her humanity has been discovered and recognised through good relations and interactions with others. This affirmation further gives recognition to the growth, gifts and abilities that one has been endowed with, the gifts that oblige one to positively contribute to the well being of others. This further demonstrates that self-interests are sacrificed and the other takes priority. 'Resources ... were used as markers and determiners of ubuntu' (Saule, 1996:87).

Ubuntu is a call to service and participation. It is to serve humanity in a practical way. Through the positive actions mentioned, one is connected, linked and bound to others. A practical communal action to alleviate human suffering is the best way one can demonstrate his contribution to society. It is a form of a principle of subsidiarity, where those who are strong help weaker 
members. Ubuntu deals with many feelings of compassion, of making life more humane for others, especially caring for the disadvantaged: the sick, the bereaved, the poor and strangers. There is a concerted effort and commitment to advance their interests. These acts help to 'bring sense not only to one's own life but also to the lives of others' (Broodryk, 1997:74). Sebidi (1988:5) drives a point home when he says 'ubuntu is humanism with the accent on the humane. It is perhaps, this aspect of ubuntu which prompted the Senegalese ex-President, Leopold Senghor, when he writes: emotion is African; '... ubuntu is primarily emotionally or feelingly humane'.

\section{Ubuntu/Botho in Relation to Strangers}

Having explained what ubuntu is about, especially its components of respect for people and the need to be in community in order to be able to assist one another, we will now turn to the attitudes of Africans towards strangers. These attitudes, as one would realise, are underpinned by respect for persons and all that goes with this respect. The attitudes of Africans towards foreigners or strangers in the past were those of tolerance and benevolence. Strangers were made to feel welcome and to move with ease within the community.

Strangers were referred to as visitors, guests (iindwendwe) or aliens, sojourners (abahambi). These words have positive connotations. They aroused feelings of saying, you are welcome, we will help you and we respect you. The position of these people as abahambi or indwendwe made it easier for the hosts to welcome them because they were people who come today and would be gone the other day (Shack \& Skinner, 1979:37). They were not part of the family, tribe or group and their stay among the group was temporary. These people were treated with respect and were shown hospitality. Iimbacu (refugees), as people who are homeless, alienated from their land and families were treated with compassion and kindness. They were regarded as abantu abahlelelekileyo (people who are deprived, poor). Because of their position of deprivation, they were given special treatment, such as being allocated land. Some of them merged with the local people. Their security at times lay in their absorption through cultural assimilation and intermarriages. It was inculcated into people's minds to be 
conscious of strangers. There are proverbs that call upon people not to ill-treat or close a door to a stranger but to show him/her hospitality. One of the proverbs is, unyawo alunampumlo (Xhosa)/ Looto ha lena nko (Sotho) (lit. the foot has no nose); that is, one should beware of one's unkind actions since they have a way of turning against the doer. Since no one knows when one will be a stranger in a foreign land and in need of hospitality or good treatment, one, therefore, should not place a stumbling block or be a hindrance to a stranger. This proverb means that one has an extensive obligation to admit, and to be generous and supportive to strangers. Similar words were uttered some years ago by a refugee from Sudan, when he said, the manner in which we now look to you for help today may be the way you will be looking to others tomorrow. The reasoning is that we must realize that whatever we are able to do for 'people on the move' while we have the opportunity, we are doing for ourselves as well as for others (Kifle 1991:260). Even though this proverb seems to be based on selfinterest - reciprocity, because caring will be advantageous to one day - it is instilled as an obligation of love and caring. This was not just a matter of justice but of love. For a person to be harmed while staying or passing through a particular village, that would bring a sense of shame, grief and scandal to the whole area. A stranger was a good advertisement for a particular family or village, especially if he or she was treated with openness and friendliness. On his or her way home and back at home, the visitor would be able to talk positively about the hosts and the good treatment one had received.

People are encouraged to be generous and to give food to strangers: Isisu somhambi asingakanani, singaphambili, ngemva ngumhlonzo (Lit. The stomach of a traveller is not big, it is only in front, it is limited by the spine). This proverb tells us about the people's readiness to help, feed and protect a stranger. This is confirmed by Saule (1996:86) when he says, 'In any Xhosa household a stranger or a visitor is a respected person. He/she is treated cordially, given water to wash, food to eat and a place to sleep. He/she would in turn spread the good news about that particular household'.

Indeed, travellers or strangers were served with food unreservedly. Their presence was seen as more of a blessing than a 
burden and this further brought joy to children since they knew that best meals would observed. That is why among the Batswana there is a saying, Moeng goroga re je ka wena (come visitor so that we can feast through you). This proverb is a call to be ever generous to a stranger. It is also a revelation about attitudes one needs to have in using resources that one has acquired. Giving food to strangers was more than just satisfying their physical hunger but was a 'barometer of social relations and a powerful mechanism for both creating sociability and alternatively, for destroying it' (Martin and Davids, 1997:1104). It was a challenge to the host to open one's boundaries and be receptive and generous to the stranger.

These proverbs demonstrate and reveal the moral lesson and values, friendliness, benevolence and the deep concern of African people towards strangers. Strangers were accepted, trusted and seen as people who had dignity and, therefore, needed to be accorded respect. Their needs were recognized and there was a genuine attempt to meet them as far as it was humanly possible. There was a feeling for their plight of being away from home, of being in need of food, shelter, rest, protection and so on. Attempts were made for them to socialise and to give them solidarity. They were made to feel at home and shown hospitality. Such positive attitudes and actions also created stability because strangers knew what to expect and what was expected of them.

What one discovers here is the fact that the presence of the other did not threaten or inhibit. But it aroused feelings of respect, compassion, reaching out and acceptance. In essence, ubuntu, indeed, made all people each other's keepers. This also demonstrates the value of hospitality that was espoused by African society. This society was not individualistic and selfish but practical and beneficial to the one in need. Hospitality 'was a public duty toward strangers where the honor of the community was at stake and reciprocity was more likely to be communal rather than individual [,]...hospitality ...was a sacred duty' (Martin and Davids 1997:501). This sense of hospitality was combined with making sure that the guest was protected from being harmed during the length of his or her stay. Such protection demonstrates that there is a greater respect for human life and human beings were to be protected from inhuman 
abuses. These proverbs further reveal that strangers had rights and privileges that needed to be guaranteed and guarded. The proverbs referred to further demonstrate that no one is a stranger. The world is our common home, the earth the property of us all because human life only exists by being shared, so all that is necessary for that life, for living and living well, is shared by the human family as a whole (Hartin, Decock \& Connor, 1991:189).

One has to agree with Shack and Skinner (1979:8) when they say that it "would be romantic fantasy to suggest that prior to [the colonial and apartheid era] the receptivity to African strangers by their African hosts was in every situation characteristically amicable and devoid of hostility. This is not so'. Among the AmaXhosa, for example, all non-Xhosa speaking Africans, that have not been assimilated are still referred to as iintlanga (other nations). It has a negative connotation. It makes social distinctions among Africans real. This word has also acquired a derogatory meaning and it is discriminatory. It refers to strangers as some kind of secondclass people. They are seen as outsiders, as the 'other' since they have a culture and a language, which are different from the 'norm'. The AmaXhosa are the nation and the 'people', others are the nations and peoples. To be human is to belong to this group. As Shack and Skinner (1979:41) point out, though, 'overt expression of such distinction through hostile acts never received official sanction'. These people, though labelled, moved with ease. They were still entitled to hospitality and respect.

Whilst it can be seen that though ubuntu is an important value, it is an ideal, which is sometimes very difficult to fulfill. In spite of all this, ubuntu has managed to create a society which, according to Biko (1978:46), is 'a true man-centred society whose sacred tradition is that of sharing'. For a person to have ubuntu, among Africans, is considered to be highly important. It is a sign of being and becoming a person.

\section{Negative Influence On Ubuntu/Botho}

Mynata (2003) has already explained ubuntu/botho as a concept that promotes respect for persons and challenges people to be a community that is caring, accepting and compassionate. One can begin to ask, why, (in the light of xenophobia and other bad things 
that are happening) are people behaving as if this spiritual foundation is non-existent or seems to be diminishing among South Africans? One has to agree with Pityana (1999:142) when he states that moral virtues, values and obligations change.

The changing moral rules may not always be noticeable. They change even as those who abide by them insist that they are conservative. It is only that they do not notice. When they get noticed, there may be resistance. The very nature of morality, therefore, is that it is conservative because it seeks to preserve the structure of society.

Ubuntu, like all philosophies of life, has not escaped unscathed by the influences of certain events and factors in life. These influences and changes on ubuntu have not been so gentle or unnoticed. Through the centuries, African culture has always been threatened, challenged, misused and almost destroyed. Saule (1996:86) has this to say in this regard, 'Traditional religious forms of worship and customs of which kings and chiefs were custodians, were destroyed. Needless to say these forms were the very roots of ubuntu'. The following factors contributed to a certain extent to what Biko (1978:96) calls the 'process of bastardisation' of ubuntu or loss of ubuntu as a value. Metz (2007) also posits:

There are three major reasons why ideas associated with ubuntu are often deemed to be an inappropriate basis for a public morality in today's South Africa. One is that they are too vague; a second is that they fail to acknowledge the value of individual freedom; and a third is that they fit traditional, small-scale culture more than a modern, industrial society.

\section{Colonization}

In an attempt to resolve the contradiction between ubuntu and xenophobia we attempt to draw from the African experience of colonization where through the generosity of the hosts to white strangers, black people in Africa lost their land and 'all that goes along with it. Land is the basis of African self-respect and creativity. ...The loss of land meant, therefore, the enslavement of black people, their exploitation and political domination and loss of political 
power' (Mofokeng 1983:23). This also meant a loss of or alienation from their culture, which was the embodiment of values that brought the community together. Their culture was 'judged to be inferior by the culture of the conqueror and accepted to be so by the black vanquished people' (Mofokeng 1983:23). Moyo et al (cited by Saule 1996:89) acknowledge and emphasize this point when they say Colonialism, wherever it sprung, did not only bear political experience but more fundamentally the pollution and destruction of traditional practices of the indigenous people. The values and cultures of such people were profoundly disturbed and confused. It divorced itself from the traditional needs of people. The era of colonization was succeeded by the even more brutal system of apartheid in South Africa.

\section{Apartheid}

Ojedokun (2006) describes apartheid as a policy introduced by the National Party government in 1948. As a political policy it came to an end in 1994. Though no longer entrenched in the statute books, its effects are still alive and felt even today. For many years it dominated all spheres of South African life, be they political, economic, social and cultural. Racial domination and exploitation of black people and the safeguarding of white supremacy and interests were some of the aims of apartheid. Barney Pityana (1999:143) is of the opinion that the purpose of the apartheid system was that Africans should have a doubtful sense of identity and self-respect; their cultural systems and values were subordinated and marginalised in the land of their birth. What this suggests is that it is possible for culture to be used for immoral ends.

Through this system the inherent dignity of black people was undermined and black people in general were made to look with wonder and awe at white achievements and values while despising their own way of life and values. The policies which were in place, such as: migratory labour, forced removals and many others, disrupted and almost destroyed African family life. Family life is the centre for educating children by parents about values and norms of society. 'Traditional education is characterised by apho kubantwana ebebephantsi kwabazali (where children were under the strict control of the parents)...' (Saule 1996:91). This African traditional structure 
was destroyed by apartheid with its disruption of African family life.

\section{Urbanisation}

Deacon (1999:32) is of the opinion that ubuntu currently exists 'mainly in South African rural areas, it being a value lost through the processes of urbanisation' because in the urban context the 'African person becomes entrenched in the reality of (western) Capitalism' (Deacon, 1999:35). With the advent of colonization and apartheid, black people were left with almost nothing but to look for employment from white people. They started moving away from their families and heading for greener pastures in urban areas and that separation took its toll on the African culture. By coming in contact with western values, African culture was influenced and changes began to take place. Because of acculturation, Africans began to adopt the way of life of the people they came into contact with. This view is supported by Saule (1996:84) when he says 'European culture and new ideas ... resulted in change in the people's lives and thinking'. That reduced the effectiveness of African tribal life as a caring system for its members.

\section{Struggle Against Apartheid}

Attempts to overthrow the apartheid government at times undermined and threatened the values people were fighting to restore. For instance, the value of life was undermined and threatened through a practice known as "necklacing" in the last years of the struggle. "Necklacing" (putting a burning tyre around the neck of a person, killing him or her) was done to those who were perceived as being against the struggle for liberation. 'This was a time of desperation during which man was reduced to bestiality' (Sparks 1990:103). In 'this situation Ubuntu took a back seat as more aggressive and abrasive competition for survival emerged' (Saule 1996:103). Values such as compassion and respect for human life were harmed. Smit (1999:24) mistakenly interprets such actions as the dark side of ubuntu.

Because it [ubuntu] seeks the greatest happiness for the greatest number, it can easily slight the rights of individuals. The majority may forget the interests of the minority. The solidarity of 
ubuntu may be for wrong reasons. Kangaroo courts and necklacing could be a result of this. It lends itself to intimidation. It is very hard for an individual to distance himself from mass action. One wonders if practices such as those mentioned were ubuntu-inspired or they were simply actions of people who went overboard in their manner of acting. There is certainly no ubuntu about what is described here.

The above are some of the factors, which negatively affected the social fabric of society on which ubuntu operated. Since ubuntu is culturally based, it became influenced and vulnerable. Ubuntu 'may have been battered nearly out of shape by the belligerent [events] it collided with, yet in essence' (Biko 1978:41) it is still in the hearts and blood of most black people.

\section{Conclusion}

(Mynaka: 2003) is clear that ubuntu is a deeply involved phenomenon and argues;

...it is a sine qua non of African living. It is a philosophy and way of life that has held society together because of its beliefs and practices and has put the person at the centre of life. There is a clear concept of morality, which contradicts the manner of behaviour, which is prevailing today. Ubuntu has values that have to do with both the character and behaviour of a person.

Though ubuntu is difficult to define, it becomes partially understood through certain human acts or an absence of those acts. These acts are motivated by a good inner state or disposition. One of the aims of ubuntu is to conserve, develop and perfect a human person. It is also about self-understanding, self preservation and growth. The role of the community in doing what we have described above is to help in shaping and defining a person. A person has rights to be respected, to be helped, protected, fed and shown compassion and love. There is no discrimination when it comes to these rights; one qualifies because one is a human person.

The rights that one had were not understood as statements about entitlement but were for giving one responsibility and 
obligation towards others. According to the value of ubuntu priority is given to both duties and rights one has as a person. People in need have a right to be helped and reached out to while others have a duty and obligation to render their services. This is not charity, but people morally feel that they should do something for the needy. This is based on the notion that the presence of the other arouses feelings of respect, kindness, compassion and sacrifice. A person's responsibility is not concealed through group effort, but one has to participate as an individual. This participation in community either enhances or decreases the individual's self-respect or recognition as a person. A person is a person by what one does. One's action either makes one umntu olungileyo (a good person) or umntu ombi (a bad person). A human person is understood as a person who possesses good qualities and puts them to good use. The inner state, a divine gift that grows through being nurtured and nourished by the constant challenges individuals and society pose to the individual, needs to be externally expressed through good actions. The potential of the individual is understood when revealed and actualised, when one reaches out to others. The understanding and carrying out of the obligations that one has, enabled by the community were to avoid things, which were destructive and harmful to other people.

A human person in isolation is understood to be incomplete; one is truly complete in community, in relation to others. There is no discrimination in this community. The community, according to ubuntu philosophy, is an authoritative source for ethical actions. Concern is not just about the individual but about the common good, the common good which is primarily about the person. The human society expects and tolerates certain types of acceptable behaviours from people. There are values, such as human persons, solidarity, cooperation and compassion, which are considered to be inviolable and indivisible. The conscience, the inner state, and feelings for the other are constantly encouraged, challenged and nourished.

Nothing can be closer to the truth than the words of Broodryk (1997:6), that if people could become more ubuntu conscious, it should lead to a more ordered, caring society based on humanity'. Ubuntu would be what Biko (1978:47) refers to as a special contribution to the world in the field of human relations, a 
great gift of 'giving the world a more human face'.

It can be argued that due to the intervention of some of the factors enumerated above the role of ubuntu has diminished and xenophobia has flourished. Therefore a reclamation of an ethical foundation rooted in Botho/Ubuntu which is an integral part of African ethics steeped in issues of liberation, development, identity will lead to a recapturing of the values and principles enshrined in the philosophy and this will ensure that South Africans have the opportunity to enjoy the dignity that they deserve and would seem to be with way out of the present xenophobic inspired attacks.

Furthermore, as Biko (1978) argues since ubuntu is still in the hearts and blood of most black people highlighting the role of political leadership will be of help, and (Dalamo: 2013:7) argues that on:

On the macro level, political leaders such as Julius Nyerere, Kenneth Kaunda and Jomo Kenyata have experimented politically, adopting some of the basic tenets of botho/ubuntu for their programmes and propounding ideas that were based on an African understanding of the family as a building block. Julius Nyerere's Ujamaa, for example, was based on the con- cept of family as a basis for a successful nation. It has to do with "community de- velopment and community upliftment" (Mcunu, 2004:38). Ujamaa wanted to recapture and "spread the values of human dignity, equality, solidarity and human rights that traditionally existed in the family" (Ng'weshemi, 2002:73) and religion was the cornerstone. Ujamaa is an ethic based on ubuntu. Kenneth Kaunda's 'African Humanism' is a humanist communitarian ethic that "exists in an African traditional society where com- munity needs take precedence over individual self-gratification" (Murove in Nicholson, 2008:105).

The paper, therefore, suggests it is possible for South African leaders to rise to this challenge, turn away from proclamations from 
politicians with the potent mix of media reporting on drug syndicates, prostitution and human trafficking, all feeding off a popular perception that migrants are bad for South African society and its economy and retrace its path to those of the African leaders past gone as evidenced above to restore ubuntu as the ethical basis of relationship in the country.

Solomon (2003) argues that it is all too easy for the media and the government to place blame on immigrants for crime, unemployment and housing problems but it is not a long-term solution and, eventually, can only be detrimental for the economy, culture, society and international image of South Africa.

*Olu Ojedokun, PhD, Faculty of Social Sciences and Entrepreneurial Studies, Lead City University, Ibadan E-mail: employlawone@aol.com. 
Ojedokun: An ethical approach to xenophobia...

\section{References}

Biko, S. 1978. I write what I like. Stubbs, A (ed). London: The Bowerdean Press.

Broodryk, J. 1997. Ubuntuism as a worldview to order society. D. Litt et Phil Thesis University of South Africa. Pretoria.

Coetzee, P.H. and Roux, A.P.J. (eds) 1998. The African Philosophy Reader. London: Routledge.

Crush, J. and Pendleton, W. (2004) Regionalising Xenophobia? Citizen attitudes to immigration and refugee policy in Southern Africa, Canada: SAMP.Institute for Democracy in South Africa.

Dalamo R (2013) Botho/Ubuntu: The Heart of African Ethics Scriptura 112 (2013:1), pp. 1-10 http://scriptura.journals.ac.za

Deacon, M. 1998. The ethics of ubuntu. Word and action 38:5-9.

Gottstein, K. 'Violent and Peaceful Settlements of Ethnic Conflicts: Some Theses on the Determinants' in Bekker and Carlton (eds.) Racism, Xenophobia and Ethnic Conflict, Durban: Indicator Press.

Harris, B. (2001) 'A Foreign Experience: Violence, crime and xenophobia during South Africa's transition', CSVR.

Hartin, P. J., Decock, P. B. and Connor, B. F. (eds). 1991. Becoming a Creative Local Church: Theological Reflections on the Pastoral Plan. Pietermaritzburg: Cluster Publications.

Kaysen, C (1996) 'Are Nations Natural Economic Units?' in Bekker and Carlton (eds.) Racism, Xenophobia and Ethnic Conflict, Durban: Indicator Press.

Kifle, M. 1991. Intra-continental patterns, Problems and Opportunities: Africa. In Reformed World, 41 (7/8): 260-265. 
Landau, L.B (ed), 2011. Exorcising the Demons Within:

Xenophobia, Violence and Statecraft in Contemporary South Africa. Johannesburg: Wits University Press; Tokyo: United Nations University Press.

Los Angeles Times "Attacks on foreigners spread in South Africa; weekend violence feared". 17 April 2015. Retrieved 18 April 2015.

Martin, R. and Davids, P. H. (eds). 1997. Dictionary of the later New Testament and its development. Leicester:InterVarsityPress.

Mazrui, AA 2009. Africa's Wisdom has Two Parents and One Guardian. In African Ethics edited by MF Murove 36-59.

Pietermaritzburg: University of KwaZulu-Natal

Mcunu, TN 2004. The Dignity of the Human Person: A Contribution of the Theology of Ubuntu to Theological Anthropology.

Unpublished Master of Theology Dissertation, University of South Africa, Pretoria.

Metz (2007), Ubuntu as a Moral Theory: Reply to Four CriticsSouth African Journal of Philosophy 26 (4):369-87 (2007)

Mnyaka, N (2003) 'Xenophobia as a response to Foreigners in Post Apartheid South Africa and Post-Exilic Israel: A Comparative Critique in the Light of the Gospel and Ubuntu Ethical Principles. Submitted in accordance with the requirements For the degree of Doctor of Theology at University of South Africa.

Mogekwu, M. (2005) 'African Union: Xenophobia as poor intercultural information’, Ecquid Novi 26(1): 5-20.

Mofokeng, T. A. 1983. The crucified among the crossbearers: Towards a Black Christology. Kampen:Uitgeversmaatschappij J.H.Kok.

Netshitomboni, S. 1998. Ubuntu: Fundamental Constitutional Value And Interpretive Aid. Master's thesis, University of South Africa. Pretoria. 
Ojedokun: An ethical approach to xenophobia...

Neocosmos, M. (2006) From 'Foreign Natives' to 'Native Foreigners', Dakar: CODESRIA

Ng'weshemi, AM 2002. Rediscovering the Human: The Quest for a Christo-Theological Anthropology in Africa. New York: Peter Lang Publishing Inc.

Nyamnjoh, F. B. (2006) Insiders and Outsiders. Citizenship and Xenophobia in Contemporary Southern Africa, London: Zed Books Ltd.

Ojedokun, O. (2006), Speaking Truth and the Works of Albie Sachs (Unpublished Ph.D Thesis), Nottingham Trent University.

Pato, L. L. 1997. Being fully human: From the perspective of African culture and spirituality in Journal of theology for Southern Africa 97 (3):52-60.

Solomon, H (2013), Xenophobia in South Africa: Reflections, Narratives and Recommendations South African Peace and Security Studies Vol 2 No 22013

Pityana, N.B. 1999. The Renewal of Moral Values in African Renaissance. Ed M.W. Makgoba. Tafelberg: Mafube.

Saule, N. 1996. Images in some of the literary works of S.E.K. Mqhayi. D.litt et Phil thesis, University of South Africa: Pretoria.

Sebidi, L.J. 1988. Towards a definition of ubuntu as African Humanism. Unpublished paper.

Shack, W. A. and Skinner, E. (eds). 1979. Strangers in African societies. Berkeley: University of California.

South Africa Online (2015) accessed on $6^{\text {th }}$ July 2015 from http://www.sahistory.org.za/article/xenophobic-violence-democraticsouth-africa 
Sparks, A. 1990. The mind of South Africa. New York: Heinemann.

Teffo, J. 1998. Botho /Ubuntu as a way forward for contemporary South Africa. Word and action. 38:3-5.

The Week (2015) South African xenophobia: why is there so much hatred of foreigners? Accessed on $18^{\text {th }}$ May 2015 http://www.theweek.co.uk/63378/south-african-xenophobia-why-isthere-so-much-hatred-of-foreigners

Tutu, D. 1999. No future without forgiveness. London: Rider.

Xenophobic violence in democratic SouthAfrica accessed $6^{\text {th }}$ July 2015 http://www.sahistory.org.za/article/xenophobic-violencedemocratic-south-africa

Xenophobia in South Africa After 1994 https://eagleman6788.wordpress.com/2015/04/18/words-for-the-dayxenophobia-xenophobia-in-south-africa-after-1994/ 